\title{
Cystic fibrosis patients and families support cross-infection measures
}

\author{
A.L. Griffiths*, D. Armstrong", R. Carzino", P. Robinson ${ }^{+}$
}

Cystic fibrosis patients and families support cross-infection measures. A.L. Griffiths, D. Armstrong, R. Carzino, P. Robinson. (C) ERS Journals Ltd 2004.

ABSTRACT: A clonal strain of Pseudomonas aeruginosa (PA) was isolated in 1999 at the Royal Children's Hospital, Melbourne, Australia, after five unrelated children with cystic fibrosis (CF) died from severe lung disease aged $<5$ yrs. Subsequently, more than half of the patients in the clinic with PA were found to harbour this strain, and segregation measures were instituted at the hospital to prevent further spread.

The aim of this study was to assess CF parent and patient responses to the segregation measures to determine overall support. A questionnaire was sent out to the families of $291 \mathrm{CF}$ children treated at the centre.

A $65 \%$ response rate was obtained. The majority of parents $(85 \%)$ and patients $\geqslant 12$ yrs old $(63 \%)$ were positive about the segregation measures instituted. A total of $11 \%$ of parents and $25 \%$ of patients were unsure, and $4 \%$ of parents and $12 \%$ of children gave negative responses. Those who were not happy listed reasons such as concerns about the emotional impact of not socialising with other CF children, inconclusive evidence about person-person spread of infection and feelings of alienation created in the clinic by the separation.

In conclusion, the majority of responding cystic fibrosis patients and their families understand and are supportive of infection control measures instituted at the Royal Children's Hospital, Melbourne, Australia.

Eur Respir J 2004; 24: 449-452.
*Dept of Respiratory and Sleep Medicine, Princess Margaret Hospital for Children, Perth, and ${ }^{\#}$ Dept of Respiratory and Sleep Medicine, Monash Medical Centre, and Depts of "Microbiology and ${ }^{+}$Respiratory and Sleep Medicine, Royal Children's Hospital, Melbourne, Australia.

Correspondence: A.L. Griffiths, Dept of Respiratory and Sleep Medicine, Princess Margaret Hospital for Children, Roberts Rd, Subiaco 6008, Perth WA, Australia. Fax: 61893408181

E-mail: mandieg@bigpond.net.au

Keywords: Clonal strain, cross-infection, family support, Pseudomonas aeruginosa, segregation

\section{Received: June 122003}

Accepted after revision: May 132004

This study was supported in part by the Royal Children's Hospital Cystic Fibrosis Research Trust (Melbourne, Australia).
In 1999, an epidemic strain of Pseudomonas aeruginosa (PA) was isolated at the Royal Children's Hospital, Melbourne, Australia, after five unrelated children with cystic fibrosis (CF) died from severe lung disease aged $<5$ yrs. The Cystic Fibrosis unit at the Royal Children's Hospital supervises the care of $\sim 300$ children with $C F$ and is one of the largest paediatric CF care centres in Australia. Newborn screening for $\mathrm{CF}$ has been employed in the state of Victoria since April 1989. Each year, 20 new patients are identified. In $1999, \sim 150$ patients in the clinic were $<9$ yrs. Between 1991 and 1996, the current authors cared for five children all $<5$ yrs who died after developing aggressive lung disease associated with mucoid PA infection. The details of these children have been included in a separate report [1]. When molecular typing identified that all deaths were associated with the same epidemic strain of PA and that over half of the Pseudomonaspositive patients in the clinic also carried this strain, it was decided that cross-infection measures would be instituted. These measures included the introduction of cohort segregation and education seminars.

Cohort segregation was based on five separate groups: PA positive $(\mathrm{n}=52)$; epidemic strain PA $(\mathrm{n}=41)$; Burkholderia cepacia (BC) $(\mathrm{n}=4)$; methicillin-resistant Staphylococcus aureus (MRSA) $(\mathrm{n}=3)$; and PA negative $(\mathrm{n}=191)$. Inpatients were nursed in separate sections and attended physiotherapy sessions at different times. Those children infected with epidemic strain PA, MRSA or BC were isolated from each other and all other patients, whereas those within the other groups were allowed to mix within their cohort groups. To introduce these new measures to the clinic, three parent education seminars were held, describing the findings and planned introduction of cohort segregation-based crossinfection measures. As $27 \%$ of the patients came from the non-metropolitan areas of Victoria, regional education sessions were held in two of the largest non-metropolitan centres. In addition, cross-infection guidelines were discussed in a regular (every 6 months) parent newsletter, which was sent to all families attending the clinic.

Two years after the introduction of these measures, parental and patient acceptance, and understanding of these guidelines were investigated, in order to identify if further educational sessions were required in specific matters of the cross-infection policies. A questionnaire was forwarded to all families with children treated at the clinic to determine whether patients and/or parents understood why these measures had been introduced, as well as their opinions as to how this had impacted on their children's CF care.

\section{Subjects and methods}

\section{Design and population}

This survey was carried out between May and December 2002, during which time the CF clinic at the Royal Children's Hospital was managing 291 patients. The initial identification of most patients in the clinic is by newborn screening. All patients are reviewed in outpatient clinics every 2-3 months and admitted to hospital for significant exacerbations of lung disease or other complications of CF. Most families are in more regular contact with the $\mathrm{CF}$ care team in the community. A questionnaire was sent out to the families of all 
291 patients in the state of Victoria and responses were returned by reply paid post.

\section{The questionnaire}

There were eight questions in total (see Appendix). Two questions allowed for written comments. The questionnaire contained an item on the overall response of parents and patients $(\geqslant 12 \mathrm{yrs})$ to the CF segregation measures. The answer was a three-point scale: positive, negative and unsure. In addition, questions were asked about knowledge and name of current sputum isolates, socialisation with other $\mathrm{CF}$ families in the community, whether segregation measures were taken outside the hospital based on children's sputum isolates and if not, why not. The questionnaire was designed de novo and has not been validated. There was no method of identifying which family completed each questionnaire. The authors felt that the patients and parents would feel more readily able to express their true opinions if they were completely anonymous.

\section{Statistics}

Chi-squared or Fisher's exact test were used to assess individual responses and to compare responses between parents and children.

\section{Results}

A $65 \%$ response rate was obtained (190 out of 291 ). A total of 114 parents completed the questionnaire alone $(60 \%)$ and 75 completed it together with a child of $\geqslant 12$ yrs $(40 \%)$. If there was more than one child with $\mathrm{CF}$ in the family, a separate questionnaire was filled out for each child. The results are summarised in the Appendix and table 1.

The parents' overall response to segregation measures was positive in $85 \%$ (160 out of 189 ), negative in $4 \%$ (seven out of $189)$ and unsure in $11 \%$ (21 out of 189) $(\mathrm{p}<0.001$; fig. 1$)$. One parent did not complete this question. In general, positive comments included: less stress from a parental view when attending clinics, a feeling that PA-negative children cough less and take less antibiotics than they used to, and requests for further infection control information and advice about measures to be taken in the community. One family of a PApositive child said they thought their child would not have acquired PA if measures had been instituted earlier. Those who were not happy listed reasons such as concerns about the emotional impact of their children not socialising with other $\mathrm{CF}$ children, inconclusive evidence about person-person spread of infection and feelings of alienation created in the clinics by the separation.

Children with $\mathrm{CF}$ ( $\geqslant 12$ yrs) who responded were positive in $63 \%$ (48 out of 76 ), negative in $12 \%$ (nine out of 76 ) and

Table 1. - Sputum isolates

\section{Pseudomonas aeruginosa}

MRSA

$47(49.5)$

Burkholderia cepacia

Staphylococcus aureus

Haemophilus influenze

Aspergillus fumigatus

No organism

4 (4)

21 (22)

3 (3)

3 (3)

$20(21)$

Data are presented as n (\%). A total of 95 out of $190(50 \%)$ sputum isolates were named (see Appendix). MRSA: methicillin resistant Staphylococcus aureus. $\mathrm{n}=95$.

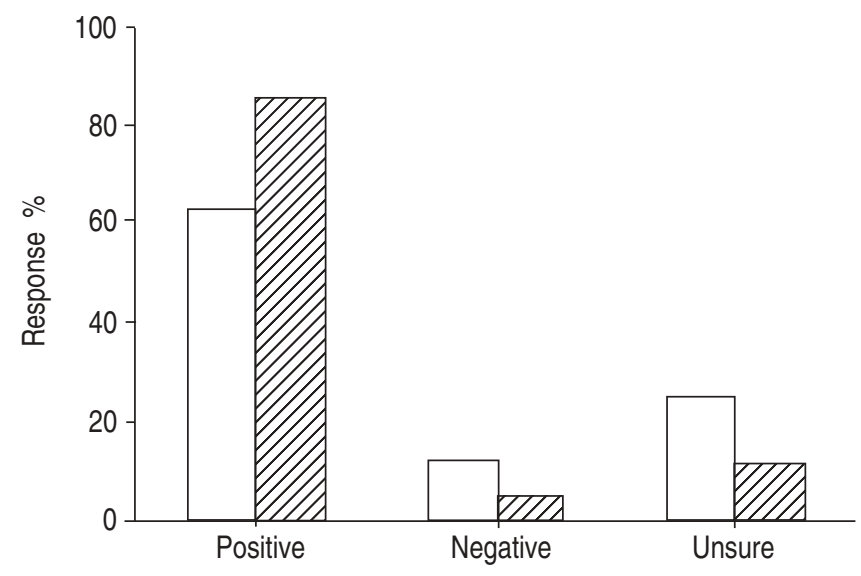

Fig. 1. - Parents' $(\mathbb{Z} ; n=190)$ and patients' $(\square ; n=76)$ overall responses to segregation measures.

unsure in $25 \%$ of cases $(19$ out of 76$)(\mathrm{p}<0.001)$. One child completed this question where the parent did not answer "parent overall response". Many children did not give any explanation about their feelings. Those who did predominantly missed their other $\mathrm{CF}$ friends. Table 2 shows a comparison of responses where parent and child both completed the questionnaire. The results were significantly different $(\mathrm{p}<0.0001)$.

In $50 \%$ of the questionnaires (95 out of 190 ), the patient's sputum isolate was known and named by either the patient or the parent. Of those who named their sputum isolate, $50 \%$ had PA (47 out of 95), 0.5\% had BC (four out of 95) and one had MRSA. The remainder named $S$. aureus, Haemophilus influenze, candida, normal flora or nil.

The majority of respondents did not have any contact with other CF families in the community (163 out of $190 ; 86 \%$ ). It is presumed that this is because it is strongly discouraged by the treating doctors. Of the 26 patients who did socialise in this way, $17(65 \%)$ parents said they considered the sputum isolates of the other child before allowing socialisation. A further 11 parents said they would consider the sputum isolates if they were to socialise with other CF families, despite saying they currently did not. The nine parents who said they did not consider the sputum isolates claimed one of the following: they were not worried about it, they did not think it was important, they did not know it was important, they found the evidence inconclusive or they did not give a reason.

\section{Discussion}

The results of this questionnaire survey suggest that the $\mathrm{CF}$ parents and patients in the Royal Children's Hospital clinic are supportive of our cohort segregation measures. It is

Table 2. - Comparison of parent and child overall responses where both completed the questionnaire

\begin{tabular}{lcccc}
\hline & \multicolumn{4}{c}{ Child } \\
\cline { 2 - 5 } & Positive & Negative & Unsure & Total \\
\hline Parent & & & & \\
Positive & 48 & 5 & 9 & 62 \\
Negative & 0 & 0 & 1 & 1 \\
Unsure & 0 & 4 & 8 & 12 \\
Total & 48 & 9 & 18 & 75 \\
\hline
\end{tabular}

Data are presented as $n$. 
speculated that the nonresponders to the questionnaire $(35 \%)$ might have higher priorities in other aspects of CF care or might be less concerned about these measures because their children have very mild CF lung disease. Of the children $\geqslant 12$ yrs who responded, fewer were positive than in the parent group. The difference was reflected by increases in those who were unsure as well as those who were negative. The unsure group may reflect true ambivalence, poor understanding of the issues or lack of opinion. The negative group was largely adolescents who had been separated from other CF companions, particularly during inpatient stays. It is, therefore, currently difficult to compare patient and parent responses in any greater detail than this. To improve understanding of responses in the adolescent age group, the current authors are planning a second questionnaire designed specifically for adolescents.

Several comments by parents suggested that they would like more information on cross-infection and segregation measures. There was only one responding parent who did not appear to understand the reasons for segregation. It is believed that it is now appropriate to reinforce parent education, given that several years have passed since the segregation measures commenced. This is particularly important in the light of new information describing a significant reduction in the prevalence of the epidemic strain of PA since the introduction of segregation measures [2].

Cohorting and careful surveillance have been used widely in the management of $\mathrm{CF}$ patients with $\mathrm{BC}$, since early reports of clustering suggested person-to-person transmission [3] and indirect (nosocomial) spread by environmental contamination [4]. After detection of an epidemic strain of BC in Edinburgh and Manchester (UK) between 1986 and 1992, social contact outside the hospital was strongly implicated and it was suggested that guidelines to limit acquisition should not be restricted to inpatients [5]. In terms of infection control of MRSA in $\mathrm{CF}$, non- $\mathrm{CF}$ guidelines have been widely recommended and implemented [6].

Cross-colonisation and epidemic spread of multidrugresistant PA between CF patients has been observed only in some studies [7] and, hence, measures directed towards infection control of PA vary between institutions. In Denmark, cohort isolation was introduced in 1981 for the first PA isolate and further subcohorting in 1983 upon identification of an epidemic strain. Combined with intensive antibiotic therapy, this has led to significant reductions in incidence of chronic PA infection [8]. Similar segregation practices have been adopted elsewhere based on evidence from genomic fingerprinting that some PA strains are transmissible [9, 10]. By contrast, such evidence was not found in Vancouver, Canada, and, hence, segregation measures are not recommended [11]. In the current authors' hospital, segregation measures were instituted in 1999 after a virulent epidemic strain of PA was isolated [1].

Although other authors have assessed CF patient perceptions of various issues, such as genetic screening [12], transition to adult care [13], chest physiotherapy techniques [14] and supportive behaviours from family and friends [15], there is currently a paucity of literature available on patient and parent responses to cohort segregation in $\mathrm{CF}$. The positive aspects have been discussed previously, but there are some important negative aspects which deserve mention. These include: the generation of a fearful attitude about becoming colonised with PA; feelings of alienation within the colonised group; socialisation limitations; and difficulties explaining to young children why they should not play with others during lengthy hospital stays [9]. Unfortunately, cohorting has caused a decline in large group education sessions, CF camps and other social gatherings, which are particularly important in empowerment of the $\mathrm{CF}$ child and adolescent. It is vital that segregated peer-support programmes continue to be encouraged, which have been said to enhance emotional wellbeing by increasing connections between chronically ill young people with CF [16].

Finally, it should be mentioned that this is not a validated questionnaire and it was designed simply to assess the general feelings and attitudes amongst the cystic fibrosis patients and families at the current authors' hospital. It has been a useful tool, which provides the impetus to design a more comprehensive instrument that may be utilised in other settings.

\section{Appendix: Questionnaire responses}

The following eight questions from the survey are shown with their corresponding answers.

1. Parent overall response: positive 160 out of $189(85 \%)$; negative seven out of $189(3.7 \%)$; unsure 21 out of 189 (11\%); not answered one out of $190(0.5 \%)$.

2. Patient overall response: positive 48 out of $76(63 \%)$; negative nine out of $76(11.8 \%)$; unsure 19 out of $76(25 \%)$.

3. Reasons for responses: general comments discussed in paper.

4. Sputum isolates known: yes 95 out of $190(50 \%)$; no 95 out of $190(50 \%)$; not answered two out of $190(1 \%)$.

5. Sputum isolates named (table 1): yes 95 out of $190(50 \%)$; no 95 out of $190(50 \%)$; not answered 0 .

6. Community socialisation with other cystic fibrosis patients: yes 26 out of $190(13.5 \%)$; no 163 out of $190(86 \%)$; not answered 1 out of $190(0.5 \%)$.

7. Community infection control measures taken: yes 17 out of $26(65 \%)$; no nine out of $26(35 \%)$; not answered 0 .

8. Reasons for not taking measures previously outlined: not answered four out of nine $(44 \%)$; don't think important two out of nine $(22 \%)$; didn't know important one out of nine $(11 \%)$; no evidence two out of nine $(22 \%)$; not worried about it three out of nine $(33 \%)$.

\section{References}

1. Armstrong DS, Nixon GM, Carzino R, et al. Detection of a widespread clone of Pseudomonas aeruginosa in a pediatric cystic fibrosis clinic. Am J Respir Crit Care Med 2002; 166: 983-987.

2. Griffiths AL, Robinson P, Carzino R, et al. Melbourne clonal strain of Pseudomonas aeruginosa since cohort segregation (abstract). Pediatr Pulmonol 2003; 36: Suppl. 25, A 345.

3. Lipuma JJ, Dasen SU, Neilson DW, Stern RC, Stull T. Person-to-person transmission of Pseudomonas cepacia between patients with cystic fibrosis. Lancet 1990; 336: 1094-1096.

4. Nelson JW, Doherty CJ, Brown PH, Greening AP, Kaufman ME, Govan JRW. Pseudomonas cepacia in inpatients with cystic fibrosis. Lancet 1991; 338: 1525.

5. Govan JRW, Brown PH, Maddison J, et al. Evidence for transmission of Pseudomonas cepacia by social contact in cystic fibrosis. Lancet 1993; 342: 15-19.

6. Guidelines on the control of methicillin-resistant Staphylococcus aureus in the community. Report of a combined working party of the British Society for Antimicrobial Chemotherapy and the Hospital Infection Society. J Hosp Infect 1995; 31: 1-12.

7. Bingen E, Botzenhardt K, Chabanon G, et al. In: Doring G, Schaffer L, eds. Epidemiology of pulmonary infections by Pseudomonas in patients with cystic fibrosis: a consensus report. Paris, Association francaise de lutte contre la mucoviscidose, 1993. 
8. Frederiksen B, Koch C, Hoiby N. Changing epidemiology of Pseudomonas aeruginosa infection in Danish cystic fibrosis patients (1974-1995). Pediatr Pulmonol 1999; 28: 159-166.

9. Denton M, Kerr K, Mooney L, et al. Transmission of colistin-resistant Pseudomonas aeruginosa between patients attending a pediatric cystic fibrosis center. Pediatr Pulmonol 2002; 34: 257-261.

10. Cheng K, Smyth RL, Govan JRW, et al. Spread of a $\beta$-lactam-resistant Pseudomonas aeruginosa in a cystic fibrosis clinic. Lancet 1996; 348: 639-642.

11. Speert DP, Campbell ME, Henry DA, et al. Epidemiology of Pseudomonas aeruginosa in cystic fibrosis in British Columbia, Canada. Am J Respir Crit Care Med 2002; 166: 988-993.

12. Conway SP, Allenby K, Pond MN. Patient and parental attitudes toward genetic screening and its implications at an adult cystic fibrosis center. Clin Genetics 1994; 45: 308-312.

13. Anderson DL, Flume PA, Hardy KK, Gray S. Transition programs in cystic fibrosis centers: perceptions of patients. Pediatr Pulmonol 2002; 33: 327-331.

14. Oermann CM, Swank PR, Sockrider MM. Validation of an instrument measuring patient satisfaction with chest physiotherapy techniques in cystic fibrosis. Chest 2000; 118: 92-97.

15. Graetz BW, Shute RH, Sawyer MG. An Australian study of adolescents with cystic fibrosis: perceived supportive and nonsupportive behaviours from families and friends and psychological adjustment. J Adolesc Health 2000; 26: 64-69.

16. Olsson CA, Sawyer SM, Boyce M. What are the special needs of chronically ill young people? Aust Fam Physician 2000; 29: 299-300. 